\title{
Association between Type of Sedation and the Adverse Events Associated with Gastrointestinal Endoscopy: An Analysis of 5 Years' Data from a Tertiary Center in the USA
}

\author{
Basavana Goudra', Ahmad Nuzat ${ }^{2}$, Preet Mohinder Singh ${ }^{3}$, Anuradha Borle ${ }^{4}$, Augustus Carlin ${ }^{1}$ and Gowri Gouda ${ }^{1}$ \\ ${ }^{1}$ Department of Clinical Anesthesiology and Critical Care, Perelman School of Medicine, Philadelphia, PA, ${ }^{2}$ Department of Endoscopy, \\ Hospital of the University of Pennsylvania, Perelman Center for Advanced Medicine, Philadelphia, PA, USA, Departments of ${ }^{3}$ Anesthesiology \\ and Critical Care Medicine and ${ }^{4}$ Anesthesia, All India Institute of Medical Sciences, New Delhi, India
}

Background/Aims: The landscape of sedation for gastrointestinal (GI) endoscopic procedures and the nature of the procedures themselves have changed over the last decade. In this study, an attempt is made to analyze the frequency and etiology of all major adverse events associated with GI endoscopy.

Methods: All adverse events extracted from the electronic database and local registry were analyzed. Although the data analysis was retrospective, the adverse events themselves were documented prospectively. These events were evaluated after subdivision into propofol-based anesthesia and intravenous conscious sedation groups.

Results: Cardiorespiratory events, including cardiac arrest, were the most common adverse events during esophagogastroduodenoscopy, while bleeding was more frequent in patients undergoing colonoscopy. Pancreatitis was the most frequent adverse event in patients undergoing endoscopic retrograde cholangiopancreatography. The frequencies of most adverse events were significantly higher in patients anesthetized with propofol. Automatic regression modeling showed that the type of sedation, the American Society of Anesthesiologists physical status classification, and the procedure type were some of the predictors of immediate life-threatening complications.

Conclusions: Clearly, our regression modeling suggests a strong association between the type of sedation as well as various patient factors and the frequency of adverse events. The possible reasons for our results are the changing demographics, the worsening comorbidities of the patient population, and the increasing technical complexity of these procedures. Although extensive use of propofol has increased patient satisfaction and procedure acceptability, its use is also associated with more frequent adverse events. Clin Endosc 2017;50:161-169

Key Words: Propofol; Cholangiopancreatography, endoscopic retrograde; Endoscopy; Colonoscopy; Morbidity

\section{INTRODUCTION}

There has been rapid growth in the number and complexity of gastrointestinal (GI) endoscopic procedures performed

Received: January 6, 2016 Revised: March 14, 2016

Accepted: March 14, 2016

Correspondence: Basavana Goudra

Department of Clinical Anesthesiology and Critical Care, Perelman School of Medicine, 680 Dulles Building, 3400 Spruce Street, Philadelphia, PA 19104, USA Tel: +1-215-279-4321, Fax: +1-215-544-1132, E-mail: goudrab@uphs.upenn.edu

(cc) This is an Open Access article distributed under the terms of the Creative Commons Attribution Non-Commercial License (http://creativecommons.org/ licenses/by-nc/3.0) which permits unrestricted non-commercial use, distribution, and reproduction in any medium, provided the original work is properly cited. during the last decade. ${ }^{1}$ In contrast to surgical procedures, the majority of GI endoscopic procedures are conducted outside of the operating rom. The extensive support that is available in the operating room, in terms of equipment and manpower, is typically absent.

Along with an increase in the number and complexity of endoscopic procedures, the type of sedation administered has undergone massive transformation. The sedation practices have varied across the country and within a country. For example, In the Northeastern United States, 53\% of all colonoscopies were performed with the use of propofol, while in the Western region only $8 \%$ used propofol. ${ }^{2}$ The same study, involving 3,168,228 colonoscopy procedures in both men and 
women (40 to 64 years old), also found a high incidence of all complications, both sedation and non-sedation related, in procedures performed with propofol sedation compared to non-propofol sedation. Non-propofol sedation generally consists of a short-acting benzodiazepine like midazolam and a short-acting opioid like fentanyl. All complications were increased by $13 \%$. Specifically, these compilations included colonic perforation, hemorrhage, and stroke. In a similar study, Cooper et al. ${ }^{3}$ demonstrated a higher incidence of aspiration pneumonia in patients sedated with propofol. In this population-based analysis, a total of 165,527 procedures performed in 100,359 patients, including 35,128 procedures with anesthesia services $(21.2 \%)$, were analyzed. The multivariate analysis concluded that use of anesthesia services was associated with an increased risk of complication. The anesthesia services invariably included propofol for sedation.

The first nationwide survey of endoscopist-directed sedation practices in Korea found room for quality improvement. ${ }^{4}$ Although the postal survey had a low response rate (22\%), it found that $27.3 \%$ of all respondents performed sedation without having undergone sedation training, and $27.4 \% \mathrm{did}$ so without any formal sedation protocols. Additionally, a large number of endoscopists reported serious sedation-related respiratory events, which are normally underestimated.
Most of the data regarding serious adverse events is patchy. A detailed analysis of such events and their eventual outcome has not been attempted. Having analyzed cardiac arrest data in a similar study, we decided to analyze all serious adverse events associated with GI endoscopic procedures. ${ }^{5}$

\section{MATERIALS AND METHODS}

Institutional Review Board Approval was obtained for this study. At the hospital of the University of Pennsylvania, sedation for endoscopic procedures was provided by using either intravenous conscious sedation (IVCS) or propofol. IVCS generally consisted of a short-acting benzodiazepine like midazolam along with a short-acting opioid like fentanyl. IVCS was administered by a registered nurse under the supervision of the endoscopist who was performing the procedure, while propofol was administered by a physician anesthesiologist or a certified nurse anesthetist under the supervision of an attending anesthesiologist. Any major adverse events that occurred at any time during the hospitalization were entered into an electronic database for discussion at the Continuous Quality Improvement meeting. Additionally, adverse events that occurred during outpatient GI endoscopic procedures were

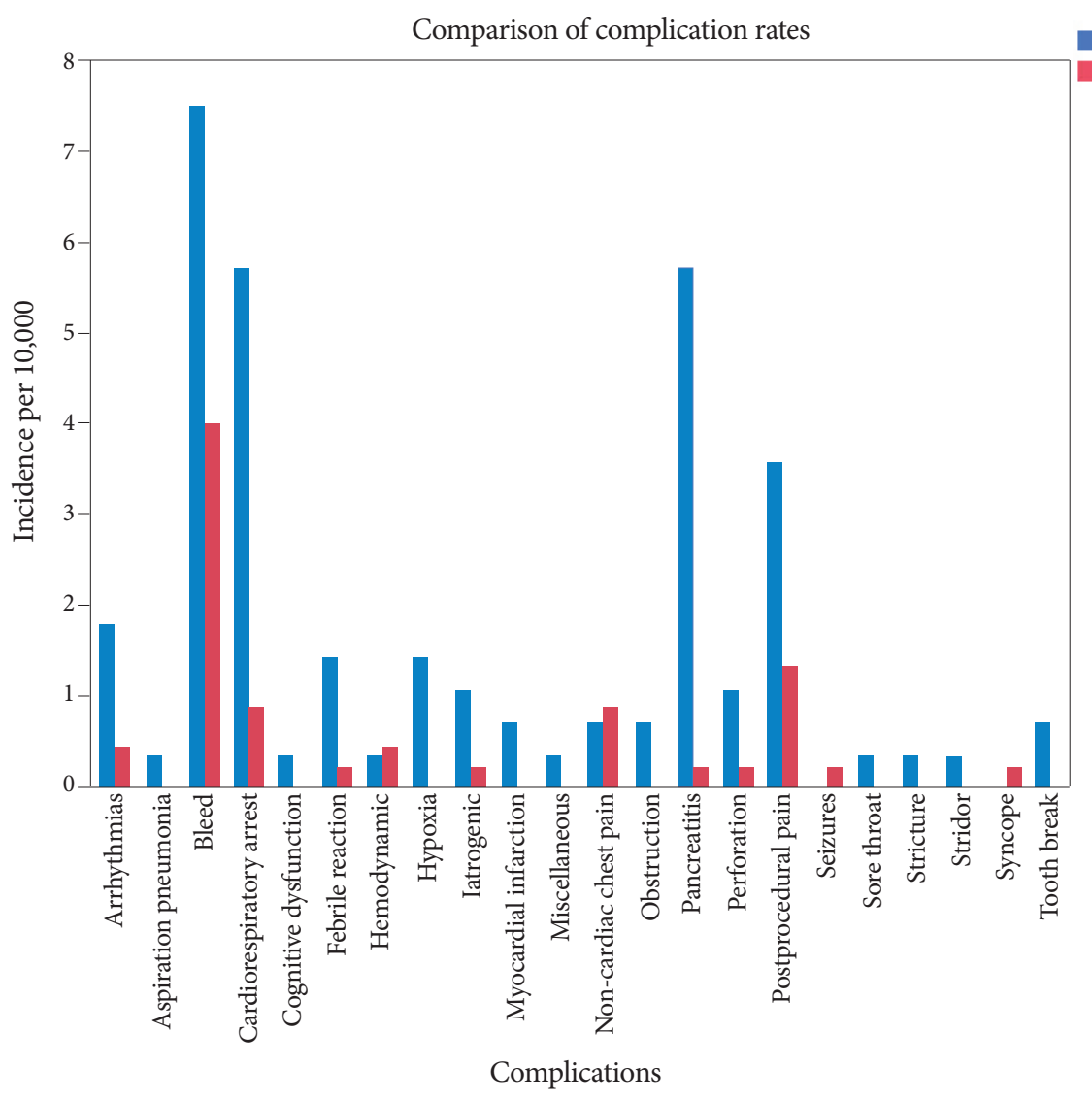

Propofol anesthesia Intravenous consicious sedation
Fig. 1. A graphical representation of the frequency of selected adverse events in patients undergoing endoscopic procedures either with propofol anesthesia or intravenous conscious sedation. 
entered into a local registry. The morbidity and mortality data were obtained from these sources for further analysis. Although the data analysis was retrospective, the adverse events themselves were entered soon after they had occurred. The denominator was provided by the billing section of the anesthesia and gastroenterology departments. The data included patients who underwent procedures between September 8, 2008 and May 31, 2013.

\section{Statistical analysis}

Statistical analysis was performed using SPSS version 23 (IBM Co., Armonk, NY, USA). The data obtained was assessed for normality using the Kolmogorov-Smirnov test. The incidence data were expressed as rate per 10,000 procedures. For factor analysis, the automated regression modeling available in SPSS was used to evaluate the contribution/relation of a factor to the outcome variable (in this case, adverse event). The available factors were combined to estimate the goodness of fit of the model for prediction of life-threatening adverse events. As the nature of sedation (propofol anesthesia or IVCS) seemed to have a significant impact on the occurrence of adverse events, we also included the type sedation as one of the determinant factors in the regression modeling (other than patient-related parameters). The results associated with a $p<0.05$ were considered statistically significant.

\section{RESULTS}

A total of 163 adverse events were reported from 73,029 procedures. These adverse events were divided into various subgroups and are presented in Table 1 and illustrated graphically in Fig. 1. As demonstrated in the table, among all adverse events, bleeding was the most common, followed by cardiorespiratory arrest, in both the propofol anesthesia and the IVCS groups. The details of the cardiorespiratory arrests were

Table 1. A Simplified Presentation of All 163 Adverse Events Associated with 73,029 Endoscopic Procedures

\begin{tabular}{|c|c|c|c|c|}
\hline \multirow{2}{*}{ Adverse event } & \multicolumn{4}{|c|}{ Frequency } \\
\hline & $\mathbf{A}$ & $\mathbf{S}$ & Not available & Total \\
\hline 1. Bleed & 21 & 18 & 12 & 51 \\
\hline 2. Cardiorespiratory arrest & 16 & 4 & 1 & 21 \\
\hline 3. Postprocedural pain & 10 & 6 & 4 & 20 \\
\hline 4. Pancreatitis & 16 & 1 & 0 & 17 \\
\hline 5. Arrhythmias & 5 & 2 & 1 & 8 \\
\hline 6. Febrile reaction & 4 & 1 & 1 & 6 \\
\hline 7. Non-cardiac chest pain & 2 & 4 & 0 & 6 \\
\hline 8. Perforation & 3 & 1 & 1 & 5 \\
\hline 9. Hypoxia & 4 & 0 & 0 & 4 \\
\hline 10. Iatrogenic & 3 & 1 & 0 & 4 \\
\hline 11. Hemodynamic & 1 & 2 & 0 & 3 \\
\hline 12. Myocardial infarction & 2 & 0 & 0 & 2 \\
\hline 13. Miscellaneous & 1 & 0 & 1 & 2 \\
\hline 14. Obstruction & 2 & 0 & 0 & 2 \\
\hline 15. Tooth break & 2 & 0 & 0 & 2 \\
\hline 16. Anaphylaxis & 0 & 0 & 1 & 1 \\
\hline 17. Aspiration pneumonia & 1 & 0 & 0 & 1 \\
\hline 18. Cognitive dysfunction & 1 & 0 & 0 & 1 \\
\hline 19. Dyspnoea & 0 & 0 & 1 & 1 \\
\hline 20. GI obstruction & 0 & 0 & 1 & 1 \\
\hline 21. Seizures & 0 & 1 & 0 & 1 \\
\hline 22. Sore throat & 1 & 0 & 0 & 1 \\
\hline 23. Stricture & 1 & 0 & 0 & 1 \\
\hline 24. Stridor & 1 & 0 & 0 & 1 \\
\hline 25. Syncope & 0 & 1 & 0 & 1 \\
\hline Total & 97 & 42 & 24 & 163 \\
\hline
\end{tabular}

A, anesthesia provider administered sedation; S, gastrointestinal endoscopist directed sedation; GI, gastrointestinal. 
Table 2. Frequency and Incidence (per 10,000 Procedures) of Selected Adverse Events in Patients Undergoing Esophagogastroduodenoscopy

\begin{tabular}{|c|c|c|c|c|c|c|c|}
\hline \multirow{2}{*}{ Adverse event } & \multicolumn{2}{|c|}{$\mathrm{A}(n=14,534)$} & \multicolumn{2}{|c|}{$S(n=16,907)$} & \multirow{2}{*}{$\begin{array}{c}\text { NA } \\
\text { Frequency }\end{array}$} & \multicolumn{2}{|c|}{ Total $(n=31,441)$} \\
\hline & Frequency & Incidence & Frequency & Incidence & & Frequency & Incidence \\
\hline Cardiorespiratory arrest ${ }^{\mathrm{a})}$ & 13 & 8.940 & 0 & 0 & 1 & 14 & 4.433 \\
\hline Postprocedure pain & 4 & 2.751 & 3 & 1.770 & 3 & 10 & 3.167 \\
\hline Bleed & 3 & 2.063 & 3 & 1.770 & 2 & 8 & 2.533 \\
\hline Non-cardiac chest pain & 2 & 1.375 & 2 & 1.180 & 0 & 4 & 1.267 \\
\hline Arrhythmias & 2 & 1.375 & 0 & 0 & 1 & 3 & 0.950 \\
\hline Hypoxia & 3 & 2.063 & 0 & 0 & 0 & 3 & 0.950 \\
\hline Perforation & 3 & 2.063 & 0 & 0 & 0 & 3 & 0.950 \\
\hline Iatrogenic & 2 & 1.375 & 0 & 0 & 0 & 2 & 0.633 \\
\hline Myocardial infarction & 2 & 1.375 & 0 & 0 & 0 & 2 & 0.633 \\
\hline Pancreatitis & 2 & 1.375 & 0 & 0 & 0 & 2 & 0.633 \\
\hline Tooth break & 2 & 1.375 & 0 & 0 & 0 & 2 & 0.633 \\
\hline Anaphylaxis & 0 & 0 & 0 & 0 & 1 & 1 & 0.317 \\
\hline Cognitive dysfunction & 1 & 0.688 & 0 & 0 & 0 & 1 & 0.317 \\
\hline Hemodynamic & 0 & 0 & 1 & 0.590 & 0 & 1 & 0.317 \\
\hline Obstruction & 1 & 0.688 & 0 & 0 & 0 & 1 & 0.317 \\
\hline Seizures & 0 & 0 & 1 & 0.590 & 0 & 1 & 0.317 \\
\hline Sore throat & 1 & 0.688 & 0 & 0 & 0 & 1 & 0.317 \\
\hline Stricture & 1 & 0.688 & 0 & 0 & 0 & 1 & 0.317 \\
\hline Total & 42 & 28.883 & 10 & 6 & 8 & 60 & 19.000 \\
\hline
\end{tabular}

A, anesthesia provider administered sedation; S, gastrointestinal endoscopist directed sedation; NA, not available.

${ }^{a)}$ Statistically significant different values using chi-square test $(p<0.05)$ are marked.

Table 3. Frequency and Incidence (per 10,000 Procedures) of Selected Adverse Events in Patients Undergoing Endoscopic Retrograde Cholangiopancreatography

\begin{tabular}{|c|c|c|c|c|c|c|}
\hline \multirow{2}{*}{ Adverse event } & \multicolumn{2}{|c|}{ A $(n=3,694)$} & \multicolumn{2}{|c|}{$S(n=1,545)$} & \multicolumn{2}{|c|}{ Total $(n=5,239)$} \\
\hline & Frequency & Incidence & Frequency & Incidence & Frequency & Incidence \\
\hline Pancreatitis ${ }^{\text {a) }}$ & 14 & 37.900 & 1 & 6.472 & 15 & 28.631 \\
\hline Bleed $^{\text {a) }}$ & 5 & 13.535 & 0 & 0 & 5 & 9.544 \\
\hline Febrile reaction $^{\text {a) }}$ & 4 & 10.828 & 0 & 0 & 4 & 7.635 \\
\hline Cardiorespiratory arrest & 2 & 5.414 & 1 & 6.472 & 3 & 5.726 \\
\hline Postprocedural pain & 2 & 5.414 & 0 & 0 & 2 & 3.818 \\
\hline Arrhythmias & 1 & 2.707 & 0 & 0 & 1 & 1.909 \\
\hline Hypoxia & 1 & 2.707 & 0 & 0 & 1 & 1.909 \\
\hline Iatrogenic & 1 & 2.707 & 0 & 0 & 1 & 1.909 \\
\hline Miscellaneous & 1 & 2.707 & 0 & 0 & 1 & 1.909 \\
\hline Total & 31 & 83.920 & 2 & 12.945 & 33 & 62.989 \\
\hline
\end{tabular}

A, anesthesia provider administered sedation; S, gastrointestinal endoscopist directed sedation.

${ }^{\text {a) }}$ Statistically significant different values using chi-square test $(p<0.05)$ are marked.

analyzed in a separate study with its own protocol and are published elsewhere. ${ }^{6}$ Briefly, the cardiorespiratory arrest data included all patients who either sustained cardiac arrest and survived or who died in the hospital due to procedure-related factors. Some of these cardiac arrests were hypoventilation related, although comorbidities and postprocedural events played a considerable role.

However, this study analyzed all of the serious adverse events, not only the cardiac arrests and deaths. The relative numbers of adverse events in the individual groups (propofol 
Table 4. Frequency and Incidence (per 10,000 Procedures) of Selected Adverse Events in Patients Undergoing Colonoscopy

\begin{tabular}{|c|c|c|c|c|c|c|c|}
\hline \multirow{2}{*}{ Adverse event } & \multicolumn{2}{|c|}{$\mathrm{A}(n=9,767)$} & \multicolumn{2}{|c|}{$S(n=23,536)$} & \multirow{2}{*}{$\begin{array}{c}\text { NA } \\
\text { Frequency }\end{array}$} & \multicolumn{2}{|c|}{ Total $(n=33,303)$} \\
\hline & Frequency & Incidence & Frequency & Incidence & & Frequency & Incidence \\
\hline Bleed & 13 & 13.310 & 13 & 5.523 & 10 & 36 & 10.810 \\
\hline Postprocedural pain & 3 & 3.072 & 2 & 0.850 & 1 & 6 & 1.802 \\
\hline Arrhythmias & 2 & 2.048 & 2 & 0.850 & 0 & 4 & 1.201 \\
\hline Cardiorespiratory arrest & 1 & 1.024 & 2 & 0.850 & 0 & 3 & 0.900 \\
\hline Febrile reaction & 0 & 0 & 1 & 0.425 & 1 & 2 & 0.601 \\
\hline Hemodynamic & 1 & 1.024 & 1 & 0.425 & 0 & 2 & 0.601 \\
\hline Perforation & 0 & 0 & 1 & 0.425 & 1 & 2 & 0.601 \\
\hline Aspiration pneumonia & 1 & 1.024 & 0 & 0 & 0 & 1 & 0.300 \\
\hline Dyspnoea & 0 & 0 & 0 & 0 & 1 & 1 & 0.300 \\
\hline GI obstruction & 0 & 0 & 0 & 0 & 1 & 1 & 0.300 \\
\hline Non-cardiac chest pain & 0 & 0 & 1 & 0.425 & 0 & 1 & 0.300 \\
\hline Obstruction & 1 & 1.024 & 0 & 0 & 0 & 1 & 0.300 \\
\hline Stridor & 1 & 1.024 & 0 & 0 & 0 & 1 & 0.300 \\
\hline Total & 23 & 23.549 & 23 & 9.772 & 15 & 61 & 18.317 \\
\hline
\end{tabular}

None of the values were statistically different in any of the groups.

A, anesthesia provider administered sedation; S, gastrointestinal endoscopist directed sedation; NA, not available; GI, gastrointestinal.

Table 5. Comparison of Frequency of Selected Adverse Events Showing Statistically Significant Difference between Propofol and Non-Propofol Sedation

\begin{tabular}{lccc}
\hline & Propofol & Intravenous conscious sedation & $\boldsymbol{p}$-value (chi-square test) \\
\hline Cardiac arrest & 6.069 & 0.666 & $<0.0001$ \\
Pancreatitis & 5.698 & 0.222 & $<0.0001$ \\
Postprocedure pain & 3.561 & 1.322 & $<0.0001$ \\
Febrile reaction & 1.780 & 0.222 & $<0.0001$ \\
Iatrogenic & 2.137 & 0.222 & $<0.0001$ \\
\hline
\end{tabular}

anesthesia and IVCS) are shown in Table 1. Overall, postprocedure pain was the third most common adverse event. Although, pancreatitis ranked fourth on the list, more than $90 \%$ of these cases were associated with endoscopic retrograde cholangiopancreatography (ERCP) and with a high predilection to the propofol anesthesia group. Specific incidences of complications for esophagogastroduodenoscopy (EGD) and ERCP by individual groups are displayed in Tables 2, 3. Colonoscopy is often regarded as a low risk procedure, and the complications related to it can be found in Table 4 . The total number of adverse events stated in Tables 2-4 is less than the total stated in Table 1 . The remaining adverse events occurred in a heterogeneous group of procedures like sigmoidoscopy, liver biopsy, and fecal disimpaction. It was deemed that a separate table was unnecessary to reflect all of these adverse events.

The adverse events showing statistically significant differences in both of the groups (propofol and IVCS) are presented in Table 5. These events were further divided into "immediate life-threatening" and "non- life-threating." Life-threatening adverse events included cardiorespiratory arrest, significant hypoxia (needing immediate intervention), and myocardial infarction. First, automated regression modeling was used to see the goodness of fit for the following predictors: age at surgery, body mass index (BMI), Mallampatti airway class (MMP), ${ }^{7}$ type of procedure, and type of sedative used (propofol vs. non-propofol). As the nature of the anesthesia (propofol anesthesia or IVCS) was deemed to have a significant impact on the adverse event outcome, type of sedation was included as one of the determinant factors in the regression modeling. The model showed overall predictability of $26.81 \%(p=0.010)$ for an analysis of 39 life-threatening adverse events, with the remaining 124 events labelled as non-life-threatening. Among the predictors used, a statistically significant predictive value was attained for three variables (Table 6). The highest predictability was seen for type of sedation, followed by the patient's American Society of Anesthesiologists (ASA) status and the type of procedure performed (in the order of strength, with 
Table 6. Regression Modelling for Predictors of "Immediate Life Threatening Complications"

\begin{tabular}{|c|c|c|}
\hline \multirow{2}{*}{ Factor } & \multicolumn{2}{|c|}{$\begin{array}{l}\text { Life threatening vs. } \\
\text { Non-life threatening }\end{array}$} \\
\hline & $\begin{array}{l}\text { Standardized } \\
\text { coefficients } \beta^{\text {a) }}\end{array}$ & $\begin{array}{c}\text { Statistical significance } \\
(p \text {-value })\end{array}$ \\
\hline BMI & -0.179 & 0.103 \\
\hline MMP & 0.188 & 0.112 \\
\hline $\mathrm{ASA}^{\mathrm{b})}$ & 0.243 & 0.032 \\
\hline Age at surgery & 0.056 & 0.639 \\
\hline Procedure type $e^{c)}$ & 0.210 & 0.041 \\
\hline Sedation type ${ }^{d)}$ & 0.428 & 0.002 \\
\hline Overall predictability & \multicolumn{2}{|c|}{$26.81 \%(p=0.001)$} \\
\hline
\end{tabular}

BMI, body mass index; MMP, Mallampatti airway class; ASA, American Society of Anesthesiologists.

a) The strength of association is shown by " $\beta$ coefficient" and the negative $\beta$ coefficient denotes a negative relation between factor and outcome (life threatening complications included cardiorespiratory arrest, significant hypoxia [needing immediate interven-

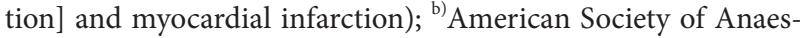
thesiologists status 3 and above is associated with higher risk life threatening events; ${ }^{c}$ Endoscopic retrograde cholangiopancreatography is associated with higher risk of life threatening events; ${ }^{\text {d }}$ Propofol sedation is associated with higher risk of life threatening events. predictability shown by standardized $\beta$ coefficient).

Considering that EGD, ERCP, and colonoscopy are associated with different types of adverse events (due to the nature of each procedure), an analysis of adverse events associated with these procedures was performed. The results distributed by group (propofol anesthesia or IVCS) are presented in Tables 2-4. In addition, the incidence of each adverse event per 10,000 procedures is also presented. Cardiorespiratory events, including arrest (defined as any cessation of cardiac activity; however, brief, requiring cardiac compressions), was the most common adverse event in patients undergoing EGD. Postprocedure pain was the second most common adverse event. The majority of the cardiac arrests with EGD occurred during the conduct of the procedure and were hypoxemia related. Once again, the incidence of almost all adverse events was highest in the patients who were sedated with propofol. Pancreatitis was the most common adverse event in patients undergoing ERCP, followed by bleeding, with rates of 1 per 300 and 1 per 1,000 procedures, respectively. Colonoscopy had a different set of adverse events. Bleeding was the most common adverse event, followed by post procedure pain. The rate of bleeding was 1 per 1,000 procedures.

Understanding that the nature of the procedure can also be a determinant of adverse event distribution, we also compared our outcomes based on the complexity of the procedures. A comparison of the types of adverse events occurring in EGD

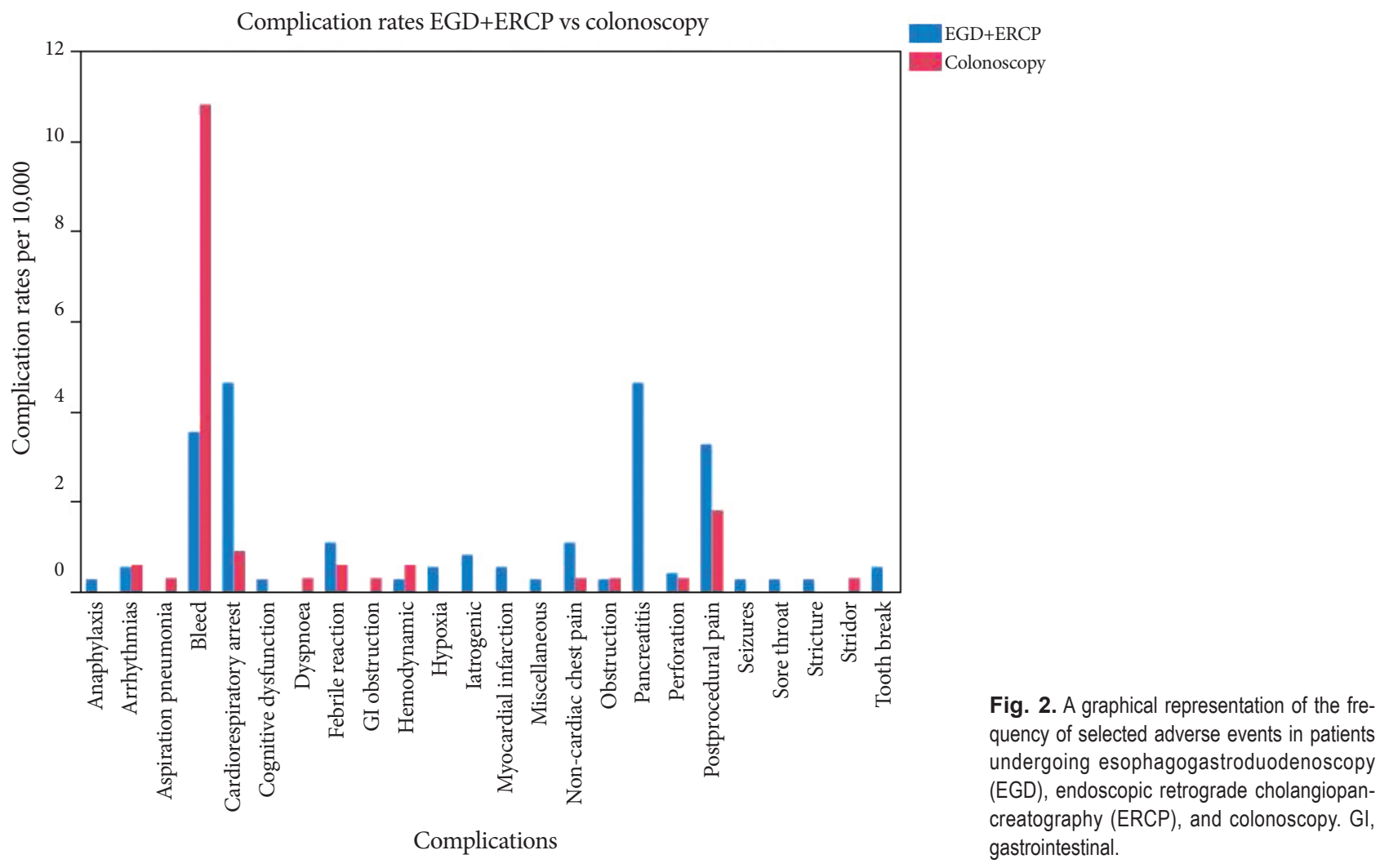


and ERCP versus colonoscopy is presented in Fig. 2.

\section{DISCUSSION}

There are significant differences between the frequency of adverse events in our study and that reported in previously published studies. An often cited study by Rex et al. ${ }^{8}$ was published in 2008. In this retrospective analysis of 646,080 (223,656 published and 422,424 unpublished) cases, there were 11 patients who required endotracheal intubation (ETT) and four deaths. In fact, only one death was hypoxemia related. The calculated frequencies of ETT and death were 0.17 and 0.06 per 10,000 cases, respectively. This is in sharp contrast to our own findings, in which the rates were at least 6.06 for ETT (as all patients who sustained cardiac arrest were intubated) and 1.91 for death. Like our study, the study was retrospective in nature. However, some of the data collected relied on the reporter's recall of past events, instead of relying on a storage system. Irrespective of the limitations of the study, the low frequency of reported adverse events is in sharp contrast to our own findings. It is important to note that all patients in all the patients in the Rex study received propofol from registered nurses under the supervision of a non-anesthesiologist, mainly gastroenterologists. The study population included patients of all ASA statuses and those undergoing advanced endoscopic procedures, including ERCP.

Two other recently published studies analyzed relatively larger numbers of patients. A multicenter German study published in 2014 involved 24,441 outpatients and reported no deaths or any other major adverse events. Three patients needed mask ventilation and one patient experienced laryngospasm. ${ }^{9}$ None of the patients needed ETT and there were no reported deaths. It should be noted that patients undergoing advanced endoscopic procedures were excluded from this study and that propofol was administered by registered nurses under endoscopist supervision.

In an Italian, single-center retrospective study that involved 17,999 procedures performed over 8 years, all patients were sedated by anesthesia providers. ${ }^{10}$ Among other events, three patients died; two from uncontrolled bleeding during the procedure and one from a bradyarrhythmia due to acute procedural distention of the bile duct. The frequency of death was 1.66 per 10,000 cases, similar to that found in our study. Cardiorespiratory adverse events were the most common, followed by aspiration. This was in contrast to our findings, which showed bleeding to be the most common adverse event. Of note, there were no deaths related to hypoxemia.

The ability to predict the likelihood of immediate life-threatening complications like cardiorespiratory arrest, myocardial ischemia, and significant hypoxia is an important aspect of our study. Most endoscopic procedures are assumed to be minor and of low risk. In spite of the limitations of the predictive model used, the model suggests the "red flags" for the likelihood of life-threatening complications. These include higher ASA grade (from III onwards), propofol-based sedation, and ERCP. Despite the model's low accuracy (26\%) for predicting such events, it can be used to alert the endoscopist and to reduce the risks. Interestingly, BMI had a negative correlation with these events (although it failed to achieve statistical significance, and we reported a similar finding in a previous study). ${ }^{1}$ This result may seem contrary to contemporary thinking and may be attributed to the fact that most anesthesia providers anticipate airway related problems in obese patients and take extra caution during the procedure. Additionally, obese patients often receive a nasal airway; thus, preventing further airway-related adverse events.

The American Society for Gastrointestinal Endoscopy has issued guidelines, with the most recent issued in 2012. In these guidelines, titled "Adverse events of upper GI endoscopy," cardiopulmonary adverse events are stated to be responsible for $60 \%$ of all events during upper GI endoscopic procedures. ${ }^{11}$ Although this may be true when all adverse events are taken into consideration, in our analysis, bleeding was the most common, followed by cardiorespiratory events. Moreover, only one of the five studies cited in the guidelines was published after 2001. ${ }^{12}$ Inclusion of more current publications might change the results. Recent changes in the landscape of endoscopy practice with regard to sedation management and procedure complexity are worthy of note. Propofol is used extensively for sedation in modern endoscopy practice. The complexity of the procedures has seen a significant change. The population demographics have changed, with elderly and obese patients forming a significant minority. In our analysis, cardiopulmonary events contribute to less than $40 \%$ of all adverse events. However, these events are severe and are often associated with cardiac arrest and death. As mentioned, the details are available for interested readers elsewhere. ${ }^{6}$

One disturbing finding of our study is an increase in the frequency of many types of adverse events in the group of patients sedated with propofol. The cardiac arrests, their mechanisms, and their outcomes were analyzed as a separate study and are being published elsewhere. Respiratory adverse events related to sedation played a significant role in patients who experienced periprocedural cardiac arrest. However, establishing a direct relationship between non-respiratory adverse events and periprocedural cardiac arrest is more difficult. It is conceivable that propofol sedation was used predominantly in patients with higher morbidity. Patients sedated with propofol had an increased incidence of bowel perforation, pancreatitis, 
post procedure pain, febrile reactions, and iatrogenic adverse events (Table 5). Cooper et al. ${ }^{3}$ reported an increase in the incidence of colonic perforation in patients undergoing colonoscopy with propofol sedation. Similar findings are reported by other investigators. ${ }^{13}$ One proposed mechanism is the diminished ability of the operator to appreciate the amount of force exerted with the endoscope due to diminished patient feedback.

Some practices might be specific to our center and might have contributed to a change in the types of adverse events seen. The incidence of hypoxemia in patients sedated with propofol is low, likely due to a proactive approach to airway management, ${ }^{1,14}$ even in patients with morbid obesity and sleep apnea. The use of a core group of anesthesiologists in the endoscopy area has facilitated the reduction of these events and shown associated cost savings. ${ }^{15}$ Some of the patients had significant comorbidity, such as implanted devices for ventricular assistance. However, the incidence of sedation-related adverse events even in this group was negligible due to modified airway management technique. ${ }^{16}$ The experiences of many other centers with advanced endoscopic procedures conducted with propofol sedation are in contrast to our experience. ${ }^{17,18}$ Variation in the method of airway management might explain these differences.

Lastly, our findings are in sharp contrast to those of studies involving non-anesthesiologist administered propofol. A meta-analysis comparing the adverse events in patients administered propofol by anesthesia providers to those in patients administered propofol by non-anesthesia providers is available. ${ }^{19}$ The study involved only advanced endoscopic procedures and showed a very low incidence of both hypoxemia and airway intervention rates when propofol was administered by non-anesthesia providers. However, in 25 of the 26 studies included in the meta-analysis the corresponding author was a gastroenterologist. Interestingly, all of the studies were published in gastroenterology journals. Only a well-designed, prospective, randomized controlled trial comparing the safety of propofol administration by the two groups can answer this question. Considering the debate involves patient safety as well as significant potential cost savings, it is important to explore the issue further.

Being retrospective in nature, the current study has certain limitations. When the data are entered into the charts, the clinician is unlikely to consider the likelihood of the data being analyzed at a future date. Incomplete data and the unavailability of important information pose unique problems. However, the large number of subjects is likely to negate this particular drawback. The same limitation is likely to have played a role in the regression modeling used in our analysis. Only a limited number of patient-related factors were available, and the adverse event severity in the charts was neither presented consistently nor standardized. In predictive models, one cannot negate the presence of undocumented factors that might have contributed to an adverse event.

Rather than investigate the contribution of causative factors for adverse events such as sepsis and pneumonia, we chose to investigate the contribution of the universally available patient characteristics age, BMI, ASA status, and MMP grade.

In conclusion, it is likely that the incidence and nature of the adverse events that occur during GI endoscopic procedures have changed over the last decade. Changing demographics and comorbidities of the patient population, in association with increasing technical complexity of the interventions performed, might explain this. Although the extensive use of propofol has increased patient satisfaction and the acceptability of GI endoscopic procedures, many types of adverse events occur more frequently in the subset of patients that receives propofol. A large, multicenter, prospective, randomized controlled trial might help to understand the mechanisms of these adverse events and their relationship to propofol use, if any.

\section{Conflicts of Interest}

The authors have no financial conflicts of interest.

\section{REFERENCES}

1. Goudra BG, Singh PM, Penugonda LC, Speck RM, Sinha AC. Significantly reduced hypoxemic events in morbidly obese patients undergoing gastrointestinal endoscopy: predictors and practice effect. J Anaesthesiol Clin Pharmacol 2014;30:71-77.

2. Wernli KJ, Brenner AT, Rutter CM, Inadomi JM. Risks associated with anesthesia services during colonoscopy. Gastroenterology 2016;150:888894.

3. Cooper GS, Kou TD, Rex DK. Complications following colonoscopy with anesthesia assistance: a population-based analysis. JAMA Intern Med 2013;173:551-556.

4. Lee CK, Dong SH, Kim ES, et al. Room for quality improvement in endoscopist-directed sedation: results from the first nationwide survey in Korea. Gut Liver 2016;10:83-94.

5. Goudra BG, Singh PM. Cardiac arrests during endoscopy with anesthesia assistance. JAMA Intern Med 2013;173:1659-1660.

6. Goudra B, Nuzat A, Singh PM, Gouda GB, Carlin A, Manjunath AK. Cardiac arrests in patients undergoing gastrointestinal endoscopy: a retrospective analysis of 73,029 procedures. Saudi J Gastroenterol 2015;21:400-411.

7. Mallampati SR, Gatt SP, Gugino LD, et al. A clinical sign to predict difficult tracheal intubation: a prospective study. Can Anaesth Soc J 1985;32:429-434.

8. Rex DK, Deenadayalu VP, Eid E, et al. Endoscopist-directed administration of propofol: a worldwide safety experience. Gastroenterology 2009;137:1229-1237.

9. Sieg A; bng-Study-Group, Beck S, et al. Safety analysis of endoscopist-directed propofol sedation: a prospective, national multicenter study of 24,441 patients in German outpatient practices. J Gastroenterol 
Hepatol 2014;29:517-523.

10. Agostoni M, Fanti L, Gemma M, Pasculli N, Beretta L, Testoni PA. Adverse events during monitored anesthesia care for GI endoscopy: an 8-year experience. Gastrointest Endosc 2011;74:266-275.

11. ASGE Standards of Practice Committee, Ben-Menachem T, Decker GA, et al. Adverse events of upper GI endoscopy. Gastrointest Endosc 2012;76:707-718

12. Sharma VK, Nguyen CC, Crowell MD, Lieberman DA, de Garmo P, Fleischer DE. A national study of cardiopulmonary unplanned events after GI endoscopy. Gastrointest Endosc 2007;66:27-34.

13. Adeyemo A, Bannazadeh M, Riggs T, Shellnut J, Barkel D, Wasvary H. Does sedation type affect colonoscopy perforation rates? Dis Colon Rectum 2014;57:110-114.

14. Goudra BG, Singh PM, Sinha AC. Outpatient endoscopic retrograde cholangiopancreatography: safety and efficacy of anesthetic management with a natural airway in 653 consecutive procedures. Saudi J Anaesth 2013;7:259-265.
15. Goudra BG, Singh PM, Sinha AC. Anesthesia for ERCP: impact of anesthesiologist's experience on outcome and cost. Anesthesiol Res Pract 2013;2013:570518.

16. Goudra BG, Singh PM. Anesthesia for gastrointestinal endoscopy in patients with left ventricular assist devices: initial experience with 68 procedures. Ann Card Anaesth 2013;16:250-256.

17. Coté GA, Hovis RM, Ansstas MA, et al. Incidence of sedation-related complications with propofol use during advanced endoscopic procedures. Clin Gastroenterol Hepatol 2010;8:137-142.

18. Barnett SR, Berzin T, Sanaka S, Pleskow D, Sawhney M, Chuttani R. Deep sedation without intubation for ERCP is appropriate in healthier, non-obese patients. Dig Dis Sci 2013;58:3287-3292.

19. Goudra BG, Singh PM, Gouda G, et al. Safety of non-anesthesia provider-administered propofol (NAAP) sedation in advanced gastrointestinal endoscopic procedures: comparative meta-analysis of pooled results. Dig Dis Sci 2015;60:2612-2627. 